www.jmscr.igmpublication.org

Impact Factor (SJIF): 6.379

Index Copernicus Value: 71.58

ISSN (e)-2347-176x ISSN (p) 2455-0450

crossref DOI: _https://dx.doi.org/10.18535/jmscr/v6i4.100

Journal Of Medical Science And Clinical Research

\title{
A Prospective Study: To Formulate a Scoring System for Prediction of Conversion from Laparoscopic Cholecystectomy to open Cholecystectomy
}

\author{
Authors \\ Dr Narendranath Swain ${ }^{1}$, Dr Y Tej Kumar ${ }^{2}$, Dr Atmaranjan Dash ${ }^{3}$, \\ Prof (Dr) Prasanna Kumar Debata ${ }^{4}$ \\ ${ }^{1,2}$ Associate Professor, Department of Surgery, SCB Medical College, Cuttack \\ ${ }^{3}$ Asst. Surgeon (Ex), Department of Surgery, SCB Medical College, Cuttack \\ Professor, Department of Surgery, SCB Medical College, Cuttack \\ Corresponding author \\ Dr Y. Tejkumar \\ Email:drsidharth74@gmail.com
}

\begin{abstract}
Aim: Laparoscopic cholecystectomy (LC) has become the gold standard of treatment of gall bladder disease, but conversion to open cholecystectomy is still inevitable certain cases. The knowledge of the rate\& impact of the causes for conversion could help the surgeon during preoperative assessment \& inform the patients accordingly. In this study we review the causes and rate of conversion to open from laparoscopic cholecystectomy.

Method and Materials: A total no. of 50 patients who were primarily posted for laparoscopic cholecystectomy, subsequently got converted to open cholecystectomy for various reasons were taken into the study. At the end of the study the various factors were assessed for the strength of association and a scoring system was formulated for prediction of conversion from LC to OC.

Observation: The conversion rate is $8.34 \%$ in this study. The commonest cause were dense adhesion $(40 \%)$, and obscure anatomy at calot"s triangle (36\%).Pre-operative high WBC count is also another cause leading to conversion. The no. of attacks with co-morbid conditions was also leads to conversion. This study includes twelve no. of parameters to formulate a scoring system to predict conversion from laparoscopic cholecystectomy to open cholecystectomy.

Conclusion: A composite scoring system was formulated comprising detail history, USG findings, and laboratory values along with co-morbid conditions which when present would help us in predicting conversion from laparoscopic to open cholecystectomy in any given patient.

Keywords: Acute Cholecystitis, Gall bladder, Laparoscopic Cholecystectomy, Conversion, Open Cholecystectomy.
\end{abstract}

\section{Introduction}

Cholecystitis in about $90 \%$ cases are due to stones (calculus cholecystitis) and in $10 \%$ cases are due to other than stone (acalculous cholecytitis). Acute cholecystitis if left untreted develops biliary colic in about $20 \%$ cases. The most common presenting symptom of acute cholecystitis is right upper quadrant pain. Other symptoms like 
nausea, vomiting, fever, pain radiating to right shoulder/scapula may also associated. Open cholecystectomy was the gold standard for symtomatic cholecystitis until the introduction of laparoscopic cholecystectomy in the 1980. Over the past 35years laparoscpic cholecystectomy has become the standard procedure for treatment of gall stone diseases. Inspite of this some cases have to be done by open conventional method keeping in mind the patient's safty and without endengering the patient's life.

\section{Material \& Method}

It is a prospective observational study done at SCBMCH, Cuttack a tertiary care hospital. Any patient for primary laparoscopic cholecystectomy who got converted to open cholecystectomy is included in this study. The total no. of patient in this study is 50 patients. The exclusion criteria are patient primarily operated with open method, patient not fit for lap. Cholecystectomy, done as a part of other surgery, age $<18$, any patient not consenting for participation. Institutional ethics committee clearance was taken. Patient's informed consent was taken. A scoring system is formulated for prediction of conversion from laparoscopic to open cholecystectomy taking different criteria into consideration.

\section{Results}

A total of 807 LC were attempted during this study of which 63 were converted to open cholecystectomy. The conversion rate is $8.34 \%$ in this study. The common cause for conversion is presence of dense adhesion $(n=20$ i.e. $40 \%)$, followed by obscure anatomy in calot "s triangle $(\mathrm{n}=19$ i.$e .36 \%)$. The youngest patient is 27 years $\&$ the eldest patient is 77years . The age group of 30 to 55 formed the major section of patients in this study $(n=33)$. (Table-1) The males who got converted are older $(\mathrm{p}=<0.05)$ by about 12 years, similarly females were more obese than male $(\mathrm{p}=$ $<0.05)$. On comparing the data regarding duration of disease, there is no significant difference amongst the genders. The difference in no. of attacks / in no. of admission was also not significantly different. Whereas the average WBC count show a significant $(\mathrm{p}=<0.05)$ suggesting a more severe inflammatory reaction in male patients.

Table-1: Demographic parameters.

\begin{tabular}{|l|c|c|}
\hline & Male $(\mathrm{n}=12)$ & Female $(\mathrm{n}=38)$ \\
\hline Age & $55.5+\_11.5 \mathrm{yrs}$ & $43.7+\_11 \mathrm{yrs}$ \\
\hline BMI & $26.8+\_1.71$ & $28.83+\_3.98$ \\
\hline Duration of disease & $8+\_6.7 \mathrm{mo}$ & $9.2+\_9 \mathrm{mo}$ \\
\hline No. of attacks & $2.41+\_0.9 \mathrm{mo}$ & $2.28+\_0.9 \mathrm{mo}$. \\
\hline No. of admission & $0.41+\_0.51$ & $0.39+\_0.54$ \\
\hline $\begin{array}{l}\text { No. of patients with associated } \\
\text { co-morbid condition }\end{array}$ & 7 & 1 \\
\hline Average WBC counts & $10830+\_1030$ & $9400+\_2250$ \\
\hline
\end{tabular}

Further analysis of data showed that the incidence of co-morbid conditions in both the gender in our study were similar $(\mathrm{p}=>0.05)$ as suggested by Chi -square test. Majority of our patients had at least 2 typical attacks suggestive of gall -stone diseases before being considered for surgery. The average number of attacks in this study is $2.3(2.32+0.91)$. The patients who required admission for gall stone related problems were found to have associated co-morbid conditions in increased frequency as compared to patients who never required admission, $n=8 / 19(42.1 \%)$ vs $n=10 / 31(32.3 \%)$. A significant proportion of patients with gall -stone disease had associated co-morbid conditions. (Table-2)

Table-2: Associated co-morbid conditions

\begin{tabular}{|l|c|}
\hline Condition & Numbers \\
\hline Hypertension & 12 \\
\hline Diabetes Mellitus & 05 \\
\hline Ischemic heart disease & 03 \\
\hline Hypothyroidism & 02 \\
\hline Bronchial asthma & 01 \\
\hline Cirrhosis of liver & 01 \\
\hline More than 1 condition & 06 \\
\hline Total no. of patients with co-morbidity & 18 \\
\hline
\end{tabular}

The above data showed hypertension is the leading co-morbid condition $(\mathrm{n}=12)$ singly or associated with other co-morbid in the patients who undergoes conversion.

Intra-operative observation shows that adhesions of gall-bladder to the surrounding structures was the commonest cause for conversion $(n=21)$, followed by difficult Calot's ( $n=19)$, followed by empyema gall-bladder in our study. The proposed 
risk stratification based on the studied parameter. (Table - 3)

Table - 3: Intra-operative observation

\begin{tabular}{|c|c|c|}
\hline $\begin{array}{c}\text { Adhesions/Difficult } \\
\text { calot/Difficulty in lifting } \\
\text { GB from Liver bed }\end{array}$ & Uncontrolled bleeding & $\begin{array}{c}\text { GB Extraction \& } \\
\text { Spillage }\end{array}$ \\
\hline Age/Sex & Deranged LFT & -Large size stone \\
Long duration of disease & Cirrhosis & -Single stone \\
NO. of attacks, & Drugs: & -Distended GB \\
H/O Acute cholecystitis & Aspirin/Heparin/Clopi & Thick GB \\
H/O ERCP & dogrel & Inadequate \\
Hot cholecystectomy & Anatomical variation & expertise of the \\
H/O Previous surgeries & in vasculature & surgeon \\
Anatomical variation & Co-morbidity; & \\
\hline
\end{tabular}

We did a back validation with the above listed risk factors to the 50 patients which were part of the study group \& scores found then as follow. With cut-off of $4 \&$ above the number of conversion would be $42 / 50(84 \%)$, while cut-off of 3 points conversion rate is $48 / 50(96 \%)$. (Table-4)

Table-4: Factors affecting intra -op. events in lap. cholecystectomy

\begin{tabular}{|l|c|c|}
\hline No & Parameter & Value \\
\hline 1 & Age & $>45$ years \\
\hline 2 & Sex & Male \\
\hline 3 & BMI & $>25$ \\
\hline 4 & Duration of complaints & $>6$ months \\
\hline 5 & Time since last attack & $<8$ weeks \\
\hline 6 & No. of attacks & $>3$ \\
\hline 7 & H/O admission & Present \\
\hline 8 & H/O Co-morbidities & Abnormal \\
\hline 9 & GB distensibility & $>$ \\
\hline 10 & GB wall thickness & $>$ \\
\hline 11 & WBC count during last attack & Increased \\
\hline 12 & Alkaline Phosphatase level \\
\hline
\end{tabular}

\section{Discussion}

Currently Lap Cholecystectomy is considered as the Gold -Standard in management of gall-stones. ${ }^{1}$ Despite so much advances ,conversion from lap to open cholecystectomy remained stable over time. It is important for the surgeon to understand that conversion is neither a failure nor a complication but is an attempt to ensure patient's safety which should be explained to the patient before. However each conversion is looked upon with a sense of failure not only to the skill of the operating surgeon but also the trust $\&$ hope that a patient bestows upon the surgeon. ${ }^{2,3}$ Conversion may be logically required in certain situation \& could help prevent possible complications most commonly encountered like haemorrhage, bile leakage, bile duct injury, peri hepatic collection, \& visceral injury. Presuming that patient selection was appropriate $\&$ surgeon is adequately trained with appropriate instruments, the conversion which occurs otherwise are the ones that deserve to be studied \& thus attempt to predict. ${ }^{3,4,5}$. Laparoscopic cholecystectomy now the most common surgery performed worldwide which is associated with tremendous variation \& is influenced by plethora of factors. It would be hard to imagine the need or temptation to predict the success or failure of the procedure. The following are the variables that determine a successful outcome in a lap. Cholecystectomy \& thus directly or indirectly affects the conversion: $, 6,7,8$. The conversion rate\& the complications associated with LC depend on the experience of the surgeon and the degree of difficulty faced during surgery. ${ }^{9,10,11 . ~ T h e ~ c o n v e r s i o n ~ r a t e ~ i n ~ o u r ~}$ study is $8.34 \%(\mathrm{n}=63)$ which is in accordance with literature. ${ }^{11,12}$. There is increased risk of conversion in elderly ( $>55 \mathrm{yrs}$ ) patients because of recurrent attacks of cholecystitis and associated co-morbid conditions. In our study the conversion rate is more in female $(n=38)$ as compared to male $(n=12)$ as opposed to other studies where no. of conver sion is more in male. Bleeding from operative area was another cause of for coversion. ${ }^{12}$. In our study $58 \%$ of conversion from $\mathrm{LC}$ to $\mathrm{OC}$ the GB wall thickness is more $>3 \mathrm{~mm}$ given by the USG previousl,y which may be related to previous inflammation \& fibrosis due to repeated attacks cholecystitis which affects the delineation of anatomy during surgrey ${ }^{13}$. Presence of comorbid conditions not only alters the physiology but also the physiological response to anaesthesia \& limiting the time duration time duration which the patient can bear the anaesthesia and the surgery $^{14,15}$. In our study patients with liver disease and COPD are primarily with open chole cystectomy.

\section{Conclusion}

In this study an attempt was made to formulate a pre operative prediction scoring system that can predict the failure of LC. The conversion rate in 
our study was $8.34 \%$. The mean age of the patient was about 46 years with pre dominantly female patients. Whereas the males who get converted are older age group. Our average patient was overweight with BMI of 28.3, with females being more obese than males .Our patients suffered at least 2 episodes of acute attacks with atleast 2 months interval from the last acute episode. A total of 19 patients had to be admitted due to complaints directly related to the gall stone disease. A total of 18 patients had associated with co-morbid conditions, the hypertension being the commonest, This group of patients required more admission \& had more frequent attacks. Comorbidities affect the patients multiple ways to contribute to conversion. The average WBC counts were $=$ normal range, however males had higher mean WBC values pointing towards more severe inflammatory process in them. The average levels of alkaline phosphatise were on the higher side $310 \mathrm{IU} / \mathrm{ml}$. A total of 31 patients had gall bladder wall thickness $3 \mathrm{~mm}$ and above, whereas 11 had filling/emptying abnormalities. The most common reason for conversion was adhesion $(n=21)$ followed by difficult Callot's triangle $(n=19)$. Patients with adhesions tends to have longer duration of disease. The results have suggested presence of high risk factors that would prelude successful 1 completion of LC : they are increasing age, male gender, obesity, no. of acute attacks, h/o admission, presence of co-morbid conditions, gall bladder wall thickness, gall bladder distensibility, total wbc count during attack, alkaline phosphatise levels. Keeping in mind patient safety \& sound surgical practices the operating surgeon should have a sensible threshold for conversion. The operating surgeon could successfully predict the conversion in $36 \%$ patients only without formal scoring system, which increased to $86 \%$ with a scoring system. The scoring system is intended to have a multilayer benefit to the patient who would be better prepared, to the surgeon who would be more sound with his decisions \& the surgery which achieve its purpose with minimum morbidity \& mortality. It can be concluded that a difficult LC can be fairly predicted based on a composite system comprising history taking, analysis of laboratory findings \& imaging of hepatobiliary system.

Source of funding: Nil

Conflict of interest: Nil

Approval of ethical committee: Taken

\section{References}

1. Bass EB, Pitt HA, Lillemoe KD; Cost effectiveness of laparoscopic cholecystectomy vs open cholecystectomy. Am J Surg 1993;165:466-471.

2. Litwin DE, Cahan MA; Lap. Cholecystectomy ;Surg. Clin. North Am. Dec 2008;88(6);1295-313.

3. Sabistan text book of surgery; $18^{\text {th }}$ edition.

4. Bellows CF, Berger DH, Crass RA; Management of gall -stones; Am Fam Physician;2005;72;637-642.

5. Daradkeh SS, Suwan Z, Abukhalaf M. Pre-operative ultra sonography and predict technical during laparoscopic cholecystectomy ;Worl J Surg 1998,22;75-77

6. Corr P, Tate JJT, Lau WY Dawson JW ; Pre operative ultrasound to predict technical difficulties and complications of laparoscopic cholecystectomy ; Am J Surgery 1994 ;168(1) 54-56.

7. Alponat A, Kum CK,Koh BC ,Rajnakova A ; Predictive factors for conversion of laparoscopic cholecystectomy ; World J surgery; 1997;21:629-633.

8. Jansen S, Jorgensen J, Caplehorn J, Hunt D;Pre-operative ultra sound to predict conversion in laparoscopic cholecystectomy. Surg. Laparosc. Endosc. 1997;7;121-123

9. Sharma SK, Thapa PB, Pandey A, Keyestha B, Poudyal S; Predicting difficulties during laparoscopic cholecystectomy by preoperative 
ultrasound ;Kathamandu University M EDICAL JOURNAL; 2007;5(17);8-11

10. Gupta N, Ranjan G, Arora M, Goswami B,Chaudhury P,et.al Vaidation of a scoring system to predict difficult laparoscopic cholecystectomy ; International J of Surgery;2013; 11(9)1102-06.

11. Soltes M, Radoak J, A risk score to predict the difficulty of elective laparoscopic cholecystectomy .Videosurgery and Other Miniinvasive surgery 2014;4;608-12.

12. Liu C; Factors affecting conversion of laparoscopic cholecystectomy to open surgery;Arch Surgery ;1996; 131 (1) ;98

13. Gupta N. Ranjan G, Arora M, Goswami B, Chaudhury P et.al. Validation of a scoring system to predict difficult laparoscopic cholecystectomy; International Journal of Surgery;2013; 11(9)100206.

14. Shapiro AJ, Cosstllo C, Harkabus M, North JH ;Predicting conversion of laparoscopic cholecystectomy for acute chole cystitis JSLS 1999 Apr-Jun 3(2) 127-130

15. Kama NA, Kologlu M, Doganay $M$, ET.AL; Arisk score for conversion from laparoscopic to open cholecystectomy. 